\title{
Hubungan Eklampsia Dengan Intrauterine Fetal Death Di RSUP Prof. Dr. R. D. Kandou Manado
}

\author{
Sjenny O. Tuju ${ }^{1}$, Syuul K. Adam ${ }^{1}$, Meylani Tologana ${ }^{1}$ \\ ${ }^{1}$ Jurusan Kebidanan Potekkes Manado \\ Email :syuulkremlin@yahoo.com; mtologana@gmail.com;olgatuju@gmail.com
}

\begin{abstract}
ABSTRAK
Latar Belakang: Kasus Kematian Ibu di Provinsi Sulawesi Utara tahun 2015 sebanyak 71 kasus. Jika dilihat dari penyebab kematian, maka kematian ibu bersalin sebagian besar disebabkan oleh perdarahan 22 kasus (30,98\%), hipertensi dalam kehamilan 13 kasus (18,03\%), infeksi 5 kasus (7,04\%), dan lain-lain 31 kasus $(43,66 \%)$.

Tujuan. Penelitian ini dilakukan untuk menganalisis hubungan faktor eklampsia dengan kejadian Intra Uterin Fetal Death.

Metode. Jenis penelitian adalah observasional dengan rancangan penelitian retrospektif study. Populasi pada penelitian ini adalah 116 kasus eklampsia di RSUP Prof Dr. R. D. Kandou Manado dengan teknik pengambilan sampel secara total sampling.

Hasil Penelitian.Hasil penelitian menunjukan bahwa dari 58 responden (50\%), terdapat $26(22,41 \%)$ responden dengan eklampsia mengalami IUFD, 32 (27,58\%) tidak mengalami IUFD dan 58 (50\%) responden merupakan sampel kontrol.

Kesimpulan. Ada hubungan yang bermakna antara Eklampsia dengan Intra Uterine Fetal Death dengan nilai $\mathrm{p}=0,001<\alpha(0,05)$ dengan $\mathrm{OR}=2,0$.

\section{Kata Kunci : Eklampsi, Intra Uterine Fetal Death}

\section{PENDAHULUAN}

Angka kematian bayi (AKB) adalah jumlah penduduk yang meninggal sebelum mencapai usia 1 tahun yang dinyatakan dalam 1000 kelahiran hidup pada tahun yang sama. Angka kematian bayi menurut WHO (World Health Organization) dalam Profil Kesehatan Republik Indonesia Tahun 2015 bahwa di negara ASEAN (Association Of South East Asia Nations) seperti di

Singapura 3/1000 kelahiran hidup, Malaysia 5,5/1000 kelahiran hidup, Thailand 17/1000 kelahiran hidup, Vietnam 18/10 kelahiran hidup, dan indonesia 27/1000 kelahiran hidup. Anggka Kematian Bayi di Indonesia masih tinggi dari negara ASEAN lainnya jika dibandingkan dengan target dari MDGs (Millenium Development Goals) tahun 2015 yaitu 23/1000 kelahiran hidup ${ }^{(1)}$
\end{abstract}


JIDAN

Jurnal Ilmiah Bidan

Target Sustainable Development Goals

(SDGs) tahun 2030, mengurangi angka kematian ibu (AKI) hingga dibawah 70 per 100.000 kelahiran hidup dan angka kematian neonatal dan bayi hingga 12 per 1.000 kelahiran hidup (2). Menurut data WHO (World Healt Organisation) tahun 2011 jumlah kematian janin dalam kandungan di dunia mencapai 12/1000 kelahiran hidup. Wilayah asia tenggara angka kematian janin dalam kandungan mencapai 22/1000 kelahiran hidup. Tahun 2009 di Indonesia kejadian kematian janin dalam kandungan tercatat 15/1000 kelahiran hidup ${ }^{(3)}$.

Survei Demografi Kesehatan Indonesia (SDKI) tahun 2012 menunjukan angka kematian ibu (AKI) di Indonesia mencapai 359 per 100.000 kelahiranhidup. Angka ini meningkat dibandingkan dengan angka kematian ibu (AKI) tahun 2007 yaitu 228 per 100.000 kelahiran hidup. Sedangkan Capaian AKB di tahun 2012kurang menggembirakan dibandingkan target Renstra kemenkes yang ingin dicapai yaitu 24 ditahun 2014 juga target MDGs sebesar 23 per 1000 kelahiran hidup ditahun 2015. Penurunan AKB yang melambat antara tahun 2003 sampai 2012 yaitu dari 35 menjadi 32 per 1000 kelahiran hidup dibandingkan dengan Hasil Survey
ISSN 2339-1731 (print), 2581-1029 (online) Demografi Kesehatan Indonesia (SDKI) selama kurun waktu 2003-2007 diperoleh data AKB sebesar 34/1000 kelahiran hidup (4)

Kasus Kematian Ibu Provinsi Sulawesi Utara tahun 2015 sebanyak 71 kasus kematian. Jika dilihat dari penyebab kematian, maka kematian ibu bersalin sebagian besar disebabkan oleh perdarahan $22(30,98 \%)$ kasus, hipertensi dalam kehamilan $13(18,03 \%)$ kasus, infeksi 5 $(7,04 \%)$ kasus dan lain-lain $31(43,66 \%)$ kasus (5).

Jika menyesuaikan dengan target MDGs menyangkut kesehatan ibu, maka dapat dibayangkan betapa upaya yang sangat keras dan komitmen penuh dengan leadership yang tangguh untuk pencapaian target AKI meliputi: Peningkatan cakupan dan kualitas pelayanan kesehatan ibu dan bayi baru lahir/anak berdasarkan bukti ilmiah, Kerjasama lintas program dan lintas sektor terkait mitra lain, pemerintah, DPR, Organisasi Profesi, Swasta, Pemberdayaan perempuan dan keluarga dan Pemberdayaan masyarakat. Tanpa pelaksanaan strategi yang sudah ditetapkan maka besar kemungkinan capaian target MDGs untuk peningkatan kesehatan ibu melalui 
Jurnal Ilmiah Bidan

penurunan AKI tersebut sulit untuk dicapai (5)

Studi awal yang dilakukan di RSUP Prof Dr. R. D. Kandou Manado bulan Februari 2018, data yang diambil selang Januari 2017 hingga Juni 2018dari jumlah persalinan 2107orang, didapatkan data ibu bersalin yang mengalami preeklampsia 144 $(6,83 \%)$ kasus, eklampsia 58 (2,75\%) kasus dan jumlah bayi lahir mati (IUFD) 55 $(2,61 \%)$ kasus. Penelitian bertujuan untuk mengetahui hubungan faktor eklampsia dengan kejadian Intra Uterin Fetal Death.

\section{METODE}

Penelitian ini menggunakan jenis penelitian observasional dengan rancangan
ISSN 2339-1731 (print), 2581-1029 (online) penelitian retrospektif study. Populasi pada penelitian ini adalah 116 kasus eklampsia di RSUP Prof Dr. R. D. Kandou Manado dengan teknik pengambilan sampel dilakukan secara total sampling yaitu 116 sampel dimana 58 responden sebagai kasus dan 58 responden sebagai kasus kontrol.Dalam penelitian ini peneliti menggunakan cheklis dengan mengacu pada rekammedik pasien sebagai insrument penelitian. Analisis data yang digunakan adalah uji chi-Square.

\section{HASIL}

1. Gambaran umum responden

Tabel 1. Distribusi responden berdasarkan umur, paritas, kelompok eklamsia dan kelompok IUFD di RSUP Prof. Dr. R. D. Kandou Kota Manado

\begin{tabular}{lcc}
\hline \multirow{2}{*}{ Variabel } & \multicolumn{2}{c}{ Jumlah } \\
\cline { 2 - 3 } & $\mathrm{f}$ & $\%$ \\
\hline Umur & 8 & 6,89 \\
$\quad<20$ & 66 & 56,89 \\
$20-35$ & 42 & 36,20 \\
$>35$ & & \\
Paritas & 31 & 53,44 \\
$\quad<3$ & 27 & 46,55 \\
$\geq 3$ & 58 & 50 \\
Kelompok Eklamsia & 58 & 50 \\
$\quad$ Eklamsia & & \\
$\quad$ Tidak Eklamsia & 26 & 22,41 \\
Kelompok IUFD & 90 & 77,58 \\
$\quad$ IUFD & & \\
$\quad$ Tidak IUFD & &
\end{tabular}

Berdasarkan tabel 1 diatas menunjukan distribusi terbanyak berada pada kelompok umur 20 - 35 tahun yaitu $66(56,89 \%)$ responden sedangkan kelompok umur > 35 tahun $42(36,20 \%)$ 
responden dan < 20 tahun $8(6,89 \%)$ responden. Kelompok paritas < 3 yaitu $(53,44 \%)$ sedangkan kelompok paritas $\geq 3$ yaitu (46,55\%). Distribusi eklampsi sebanyak 58 (50\%) dan distribusi IUFD sebanyak $26(22,41 \%)$ kasus dan yang tidak IUFD sebanyak 90 (77,58\%) bayi.

2. Analisis bivariat

Tabel 2. Distribusi Eklampsia terhadap Intra Uterine Fetal Death di RSUP Prof. Dr. R. D. Kandou Manado

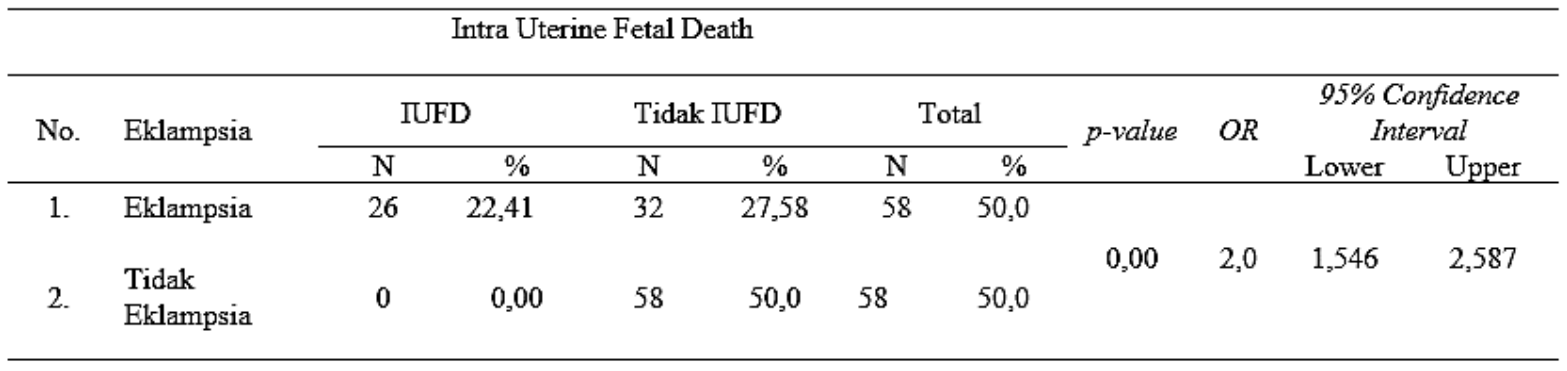

Berdasarkan data hasil analisis diatas, Tabel 2 Menunjukan bahwa pada kelompok Intra Uterine Fetal Death, pasien dengan Eklampsia sebanyak 26 responden, dan yang tidak Eklampsia sebanyak 58 responden. Pada kelompok tidak IUFD yang Eklampsia 32 responden, pada kelompok tidak eklampsia sebanyak 58 responden. Hasil uji chi-square menunjukan nilai $\mathrm{p}=$ $0,001<0,05$ artinya ada hubungan yang bermakna antara Eklampsia dengan Intra Uterine Fetal Death dan nilai OR = 2,0 yang berarti kejadian Eklampsia 2 kali lebih beresiko terjadi IUFD dibandingkan dengan tidak Eklampsia. Kemudian Convidence Interval (CI) 95\% untuk OR tersebut ialah $1,546-2,587$.

\section{PEMBAHASAN}

1. Kejadian Eklampsia
Berdasarkan hasil analisis yang dilakukan terhadap ibu bersalin sesuai dengan kriteria penelitian pada Januari 2017 dari total populasi 116 responden didapatkan $58 \quad(50 \%$ responden yang mengalami Eklampsia sebagai sampel kasus dan responden yang tidak mengalami Eklampsia yaitu $58(50 \%)$ responden sebagai kasus kontrol. Teori mengatakan Eklampsia merupakan kasus akut pada penderita preeklampsia, yang disertai dengan kejang menyeluruh dan koma ${ }^{(6)}$. Berdasarkan hasil analisis yang dilakukan terhadap ibu bersalin sesuai dengan kriteria penelitian pada januari 2017 - Juni 2018 menunjukan distribusi respondenterbanyak berada pada kelompok umur 20 - 35 tahun yaitu 66 $(56,89 \%)$ sedangkan kelompok Umur > 35 tahun $42(36,20 \%)$ responden dan $<20$ 
JIDAN

Jurnal Ilmiah Bidan

tahun $8(6,89 \%)$ responden. Terdapat banyak

faktor resiko untuk terjadinya hipertensi

dalam kehamilan yang salah satunya yaitu

umur ibu yang ekstrim ${ }^{\left({ }^{(6)}\right.}$. Berdasarkan

penelitian yang dilakukan oleh Astrina di

RSUD Panembahan Senopati Bantul menjelaskan bahwa kejadian

Preeklampsia/eklampsia banyak terjadi pada ibu dengan kelompok umur 20-34 tahun yaitu $177(72,2 \%)$ responden dan mengatakan ada hubungan yang bermakna secara statistik antara umur dengan kejadian preeklampsia/eclampsia dengan nilai $(p=0,001)^{(7)}$.

Frekuensi kejadian preeklampsia/eklampsia lebih tinggi terjadi pada primipara daripada multipara (7) Berdasarkan hasil analisis Univariate berdasarkan tabel 3 menunjukan distribusi terbanyak berada pada kelompok Paritas $<3$ yaitu $31(53,44 \%)$ sedangkan kelompok paritas $\geq 3$ yaitu $27(46,55 \%)$. Hal ini sejalan dengan penelitian yang dilakukan oleh Djannah dan Arianti di RSU PKU Muhammadiyah Yogyakarta dengan mengelompokan paritas dalam kategori Primigravida dan Multigravida dimana kejadian preeklampsia/eklampsia didominasi oleh kelompok primigravida yaitu
ISSN 2339-1731 (print), 2581-1029 (online) $82(69,5 \%)$, sedangkan multigravida 36 $(30,5 \%)^{(8)}$.

\section{Kejadian Intra Uterine Fetal Death} Berdasarkan hasil analisis yang dilakukan didapatkan distribusi kejadian Intra Uterine Fetal Death (IUFD) sebanyak $26(22,41 \%)$ kasus dan distribusi Bayi tidak IUFD sebanyak $90(77,58 \%)$ bayi dari 116 kasus.Intra Uterine Fetal Deathatau kematian janin dalam rahimadalah tidak adanya tanda-tanda kehidupan janin dan belum dikeluarkannya janin dengan sempurna dari ibunya (9). Pada preeklampsi terjadi spasme pembuluh darah disertai dengan retensi garam dan air. Jika semua arteriola dalam tubuh mengalami spasme, maka teknan darah akan naik, sebagai usaha untuk mengatasi kenaikan tekanan perifer agar oksigen jaringan dapat dicukupi maka aliran darah menurun ke plasenta dan menyebakan gangguan pertumbuhan janin dan karena kekurangan oksigen terjadi gawat janin ${ }^{(10)}$. Berdasarkan penelitian yang dilakukan oleh Sulansi dan Hendrikus di RSUD Ende mengatakan bahwa tidak terdapat pengaruh yang Signifikan terhadap kejadian IUFD. Dengan nilai $(p=0,180)$. Dengan faktor komlikasi yang menonjol adalah kejadian preeklampsia/eklampsia 
JIDAN

Jurnal Ilmiah Bidan

yaitu sebanyak 9(20,9\%) kasus

dibandingkan komplikasi lainnya (11)

3. Hubungan Eklampsia dengan Intra Uterine Fetal Death

Berdasarkan hasil analisis yang dilakukan di RSUP Prof. Dr. R. D. Kandou Kota Manado salang waktu Januari 2017 Juni 2018 dari 58 (50\%) responden yang mengalami eklampsia didapatkan distribusi kejadian IUFD berjumlah 26 atau 22,41\% responden. Berdasarkan hasil analisis Chi Square diketahui bahwa nilai p-valueI = $0,00<\alpha(0,05)$, sehingga Ho ditolak dan $\mathrm{Ha}$ diterima yang berarti ada hubungan yang bermakna antara eklampsia dengan Intra Uterine Fetal Death. Dengan nilai OR = 2,0 yang berarti kejadian eklampsia 2 kali lebih beresiko terjadi IUFD dibandingkan dengan tidak eklampsia. Kemudian convidence interval (CI) 95\% untuk OR tersebut ialah 1,546 - 2,587. Hal ini sesuai dengan pendapat Prawirohardjo yang mengatakan eklampsia tidak mempengaruhi kehamilan berikutnya, kecuali pada janin dari ibu yang sudah mempunyai hipertensi kronik. Prognosis janin pada penderita eklampsia juga tergolong buruk ${ }^{(6)}$.

Seringkali janin mati Intra Uterine atau mati pada fase neonatal karena memang kondisi bayi sudah sangat Inferior. Hal ini
ISSN 2339-1731 (print), 2581-1029 (online) sejalan dengan penelitian yang dilakukan oleh Fauziyah dengan judul hubungan antara preeklampsia dan eklampsia dengan kejadian IUFD di RSUD Brebes bahwa terdapat hubungan yang signifikan antara preeklampsia dan eklampsia dengan kejadian IUFD dengan didapatkan hasil uji Chi Square dengan taraf signifikan 5\%(0,05) didapatkan nilai $X^{2}$ hitung $=14,043$ dan nilai $P$-value $=0,05$, sedangkan nilai $\mathrm{X}^{2}$ tabel 5,991 dimana nilai $X^{2}$ hitung $(14,043)>X^{2}$ tabel $(5,991)$ dan nilai $P$-value $<0,05$. Dari hasil analisis Chi Square diketahui bahwa $\mathrm{X}^{2}$ hitung $14,043 \quad$ (12) . Preeklampsia merupakan penyebab paling umum pada kematian janin intra uterine. Sehingga, pada wanita hamil yang terdeteksi megalami preeklampsia harus diterapi dengan tepat. Terapi meliputi pemantauan tekanan darah secara teratur, disertai dengan pemantauan parameter lain seperti pertumbuhan janin, fungsi hati, dan fungsi ginjal, serta fungsi koagulasi. Dengan adanya pemantauan ini, diharapkan preeklampsia dapat dideteksi pada tahap awal dan jika diperlukan, dapat merujuk kepusat kesehatanyang lebih memadai sehingga komplikasi dari preeklampsia dapat dihindari ${ }^{(\mathbf{1 3})}$

\section{KESIMPULAN}


JIDAN

Jurnal Ilmiah Bidan

Ada hubungan yang bermakna antara

Eklampsia dengan Intra Uterine Fetal

Death.

SARAN

Rekomendasi agar mengoptimalkan

pelayanan berdasarkan standar profesi

kebidanan secara koprehensif khususnya

ISSN 2339-1731 (print), 2581-1029 (online)

Intra Uterine Fetal Death, untuk penelitian yang akan datang untuk menggunakan sampel yang lebih besar, misalnya pengambilan data dilakukan 2-3 tahun kebelakang sehingga hasil penelitian lebih akurat lagi.

dalam menangani kejadian Eklampsia dan

\section{DAFTAR PUSTAKA}

1. Kementrian Kesehatan RI. Profil Kesehatan Indonesia Tahun 2015. Jakarta: Kementrian Kesehatan RI; (2016).

2. Kementrian Kesehatan RI. Kesehatan Dalam Kerangka Sustainable Development Goals (SDGs). Rakorpop Kementeri Kesehat RI. (2015).

3. Depkes RI. Profil Kesehatan Indonesia Tahun 2011. Kementrian Kesehatan Republik Indonesia. 2011.

4. Indonesia KK. Profil Kesehatan Indonesia Tahun 2012. (2013).

5. Dinas Kesehatan Provinsi Sumatera Utara. Profil kesehatan provinsi sumatera utara tahun 2016.

Dikutip

dari: http://www.depkes.go.id/resources/download/profil/PROFIL_KAB_KOTA_2016/1275_Su mut_Kota_Medan_2016.pdf. (2016).

6. Prawirohadjo S. Ilmu Kebidanan. Jakarta: PT. Bina Pustaka Sarwono Prawirohardjo; (2014).

7. Astrina N. Analisis Faktor-faktor yang Berhubungan dengan Kejadian Preeklampsia/Eklampsia di RSUD Panembahan Senopati Bantul Tahun 2014 [Internet]. [Yogyakarta]: STIKES 'Aisyiyah Yogyakarta; (2015). Available from: http://digilib.unisayogya.ac.id/97/1/NASKAH PUBLIKASI.pdf

8. Djannah S, Arianti I. Gambaran Epidemiologi Kejadian Preeklampsia/Eklampsia di RSU PKU Muhammadiyah Yogyakarta Tahun 2007-2009. Bul Penelit Sist Kesehat. (2012);

9. Nugroho T. Buku Ajar Obstetri untuk Mahasiswa Kebidanan. Yogyakarta: Nuha Medika; (2014).

10. Nurfadila. Faktor-faktor yang Berhubungan dengan Kejadian Kematian Janin dalam Rahim (KJDR) di Rumah Sakit Khusus Daerah Ibu dan Anak Siti Fatimah Makassar. Universitas Islam Negeri Alauddin; (2013).

11. Sulansi, Mbira H. Faktor-faktor yang Mempengaruhi Kejadian IUFD di RSUD Ende Tahun 2011. Poltekkes Kupang; (2013).

12. Mazkiyah S, Kamil R, Fauziyah F. Hubungan Antara Preeklampsi dan Eklampsia dengan Kejadian IUFD di RSUD Brebes Tahun 2013. AKBID YPBHK Brebes; 2013.

13. Ayu P. Metodologi Penelitian Kebidanan dan Kesehatan Reproduksi. Yogyakarta: Nuha Medika; 2014.

Volume 5 Nomor 2. Januari-Juni 2018 